\title{
Nota Científica \\ Clonagem de Cnidoscolus quercifolius por alporquia, utilizando rejeito de vermiculita e diferentes concentrações de AIA
}

\begin{abstract}
José Aminthas de Farias Júnior ${ }^{1}$, Eder Ferreira Arriel ${ }^{1}$, Assíria Maria Ferreira da Nóbrega Lúcio ${ }^{1}$, Antonio Lucineudo de Oliveira Freire ${ }^{1}$, Rivaldo Vital dos Santos ${ }^{1}$, Rosivânia Jerônimo Lucena ${ }^{1}$
\end{abstract}

${ }^{1}$ Universidade Federal de Campina Grande, Av. Universitária, SN, Santa Cecília, CEP 58708-110, Patos, PB, Brasil

"Autor correspondente:
aminthas@gmail.com
Termos para indexação:
Substratos
Fitorreguladores
Semiárido
Impacto ambiental
Rejeito de mineração
Index terms:
Substrates
Phytoregulators
Semiarid
Environmental impact
Mining waste

Histórico do artigo:

Recebido em 23/10/2012/

Aprovado em 23/03/2015

Publicado em 31/03/2015

doi: $10.4336 / 2015 . p f b .35 .81 .499$

\begin{abstract}
Resumo - Dotada de grande resistência à seca, Cnidoscolus quercifolius Pohl (faveleira) é uma espécie que pode ser usada como forrageira, medicinal, alimentação humana, biodiesel e para recuperação de áreas degradadas. Entretanto, apresenta dificuldade de enraizamento pela técnica da estaquia e, por isto, foi avaliada a técnica alternativa da alporquia. Os tratamentos foram constituídos por substratos e concentrações de AIA (ácido indolacético). Foi observado um percentual de $46 \%$ de enraizamento no rejeito de vermiculita, com ganho significativo de matéria seca radicular. Não houve efeito significativo das doses de AIA, para as variáveis analisadas.
\end{abstract}

\section{Cloning of Cnidoscolus quercifolius by layering, using vermiculite tailings and different concentrations of IAA}

\begin{abstract}
Presenting great resistance to drought, Cnidoscolus quercifolius Pohl (faveleira) is a species that can be used as fodder, medicinal, human food, biodiesel and to restore degraded areas. However, there are difficulties regarding the technique of rooting cuttings and, therefore, it was used in this work asalternative layering technique. The treatments consisted of substrates and concentrations of IAA (indole acetic acid).There was a percentage of $46 \%$ rooting in vermiculite tailings. Vermiculite tailings yielded a significant gain of dry root matter. Regarding the doses of AIA, no significant differences were found for any variable.
\end{abstract}

A ação antrópica com a exploração de espécies nativas tem contribuído para a diminuição da variabilidade genética de muitas espécies florestais. Uma alternativa para atenuar esta devastação em áreas nativas é sua conservação ex-situ visando seu uso.

A reprodução de espécies vegetais ocorre sexuadamente, via sementes, ou através da clonagem de propágulos da planta. A alporquia representa uma alternativa viável para espécies com dificuldade de estaquia, além de não necessitar de estruturas tais como casas de vegetação ou viveiros para a produção de mudas.

O sucesso da técnica de alporquia depende de vários fatores, tais como a espécie vegetal, estádio de desenvolvimento da planta, tipo e local do ramo onde foi feito o anelamento e substrato usado. Para Hartmann et al. (2002), fatores ambientais e substâncias promotoras de enraizamento como as auxinas, também exercem papel fundamental para o êxito da técnica. 
O objetivo principal dos tratamentos envolvendo as auxinas é a indução do enraizamento adventício, principalmente em espécies de difícil enraizamento (Dias et al., 2012). Dentre os compostos com atividades auxínicas, tem-se o ácido indolacético (AIA), ácido indolbutírico (AIB), ácido naftaleno acético (ANA) e o ácido 2-4-diclorofenoxiacético, comprovadamente indutores de enraizamento.

O substrato é de importância fundamental no desenvolvimento das raízes, devendo ter boa capacidade de absorção e aeração, drenagem adequada e ser isento de pragas e doenças. A função básica é a sustentação e o fornecimento de água e oxigênio (Wendling et al., 2002). Na região semiárida da Paraíba, uma das atividades de maior expressão econômica é a mineração, destacandose a exploração de vermiculita e de caulim, que durante a lavra produzem rejeitos biologicamente inativos, que são acumulados nos pátios, provocando impacto ambiental negativo (Trajano et al., 2010).

O aproveitamento de substratos concebidos a partir de subprodutos ou rejeitos de mineração é uma alternativa tanto do ponto de vista econômico quanto ambiental, barateando os custos do processo produtivo e reduzindo a contaminação ambiental.

A faveleira (Cnidosculus quercifolius Pohl) é uma Euphorbiaceae arbórea, nativa da região semiárida. Apresenta características tipicamente xerófilas, com indicações na recuperação de áreas degradadas (Cavalcanti et al., 2009), como forrageira (Ribeiro
Filho et al., 2007), medicinal (Dantas et al., 2003), para alimentação humana (Nóbrega, 2001) e biodiesel (Silva et al., 2007), com potencial de agregação de renda, redução do desemprego e da fome de milhares de famílias na Região Nordeste do Brasil. Apesar de sua grande importância, não existem informações disponíveis sobre técnicas adequadas para a propagação vegetativa da espécie.

Objetivou-se, neste trabalho, avaliar diferentes concentrações de AIA e a eficiência do substrato rejeito de vermiculita no enraizamento de alporques de faveleira.

Foram utilizadas, no experimento, árvores matrizes adultas em fase reprodutiva de $C$. quercifolius (faveleira) de ocorrência natural. As diferentes concentrações de AIA foram dissolvidas em solução hidroalcoólica a 50\%. A solução de AIA foi aplicada nas concentrações de 0,0 ; 2,$0 ; 4,0 ; 6,0$ e $8,0 \mathrm{gL}^{-1}$. Foram utilizados o substrato comercial vermiculita expandida de textura média e o rejeito de vermiculita, que foi coletado na mina Pedra Lavrada, localizada no município de Santa Luzia, PB. O rejeito foi passado em peneira com abertura máxima de 2 $\mathrm{mm}$ de diâmetro para uniformização de suas partículas. Em cada alporque foi utilizado um volume de $600 \mathrm{~cm}^{3}$ de substrato. Amostras dos substratos utilizados foram analisadas no Laboratório de Solos do CSTR/UFCGCampus de Patos, para a caracterização de alguns atributos químicos e densidade na Tabela 1.

Tabela 1- Atributos químicos e densidade dos substratos usados nos alporques de C. quercifolius (Patos, PB, 2010).

\begin{tabular}{|c|c|c|c|c|c|c|c|c|c|c|}
\hline & $\mathrm{pH}$ & $P$ & $\mathrm{Ca}$ & $\mathrm{Mg}$ & $\mathrm{K}$ & $\mathrm{Na}$ & $\mathrm{H}+\mathrm{Al}$ & CTC & \multirow{2}{*}{$\begin{array}{l}\mathrm{V} \\
\%\end{array}$} & \multirow[b]{2}{*}{$\operatorname{Dg}\left(\mathrm{g} \cdot \mathrm{cm}^{-3}\right)$} \\
\hline Sub & $\mathrm{CaCl}_{2}$ & $\mathrm{mg} \cdot \mathrm{kg}^{-1}$ & \multicolumn{6}{|c|}{ 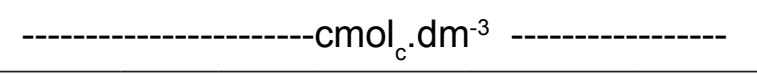 } & & \\
\hline 1 & 6,8 & 40 & 3,8 & 2,4 & 0,2 & 2,0 & 1,0 & 9,6 & 89 & 0,2 \\
\hline 2 & 5,6 & 12 & 4,4 & 1,6 & 0,3 & 1,0 & 1,5 & 8,8 & 83 & 1,4 \\
\hline
\end{tabular}

$1=$ rejeito de vermiculita; 2 = vermiculita CTC = capacidade de troca de cátions; $\mathrm{V}=$ saturação por bases 
Preliminarmente, foi realizado um teste de capacidade de retenção de água em ambos os substratos, para definir a quantidade de água necessária para umedecêlos. A capacidade de retenção de água dos mesmos foi semelhante, sendo utilizado o valor médio de $130 \mathrm{~mL}$ de água por alporque para mantê-lo a uma umidade equivalente aproximada de $70 \%$ da capacidade de retenção de água. Os substratos nos alporques foram umedecidos com o auxílio de uma seringa plástica graduada.

Para a instalação dos alporques, foram utilizadas 19 matrizes contendo ramos saudáveis, vigorosos e com folhas. Os alporques foram feitos de forma aleatória nas plantas, utilizando-se, no máximo, 10 alporques por árvore, dependendo da quantidade de galhos saudáveis disponíveis.

Os alporques foram estabelecidos de abril a maio de 2010. Inicialmente, foram anelados, com um canivete, ramos com diâmetro entre 1 e $2 \mathrm{~cm}$, removendo-se completamente a casca. Os anéis mediam cerca de $1,5 \mathrm{~cm}$ de largura, situando-se aproximadamente 60 $\mathrm{cm}$ abaixo do ápice. Em seguida, o AIA foi aplicado sobre a superfície anelada com o auxílio de um pincel. Logo após, o ramo foi recoberto com um filme plástico transparente com as duas extremidades (inferior e superior) abertas. O filme plástico foi amarrado em uma das extremidades do ramo. Em seguida, foi adicionado o substrato e a quantidade de água definida para o umedecimento do alporque. A outra extremidade do filme plástico foi amarrada ao ramo. Todos os alporques foram envolvidos com papel alumínio para reduzir a radiação excessiva e a concomitante produção de auxinas endógenas, além de interferir no balanço hídrico interno.
Após 30 dias, foram adicionados $30 \mathrm{~mL}$ de água em cada alporque com uma seringa munida de agulha, procedimento este repetido a cada 15 dias até o final do experimento. A umidade nos alporques e o surgimento de raízes no interior dos filmes plásticos foram monitorados até 90 dias.

Os ramos alporcados foram removidos das plantas matrizes com o auxílio de tesoura de poda e retirados os filmes plásticos para a contagem do número de alporques enraizados. Nos alporques enraizados, foi analisado o número de raízes e massa seca das raízes (g). Após a contagem, estas foram extraídas dos alporques, acondicionadas em sacos de papel e colocadas em estufa a $65^{\circ} \mathrm{C} \pm 0,5^{\circ} \mathrm{C}$, por aproximadamente 3 dias, até peso constante, medido em gramas.

Foi utilizado delineamento experimental de blocos inteiramente casualizados (DBC), em esquema fatorial 5 x 2 (cinco concentrações de AIA e dois substratos), com 10 repetições. Cada parcela foi constituída por um alporque, totalizando 100 parcelas. Os dados da porcentagem de enraizamento, número de raízes e massa seca das raízes foram transformados em $\sqrt{\mathrm{X}+0,5} \mathrm{e}$ submetidos às análises de variância e de regressão, conforme delineamento proposto, com o auxílio do programa estatístico "ASSISTAT" (Silva \& Azevedo, 2006). As médias foram comparadas através do teste de Tukey, ao nível de 5\%.

As porcentagens acumuladas de alporques enraizados de C. quercifolius, em função das doses de ácido indolacético (AIA) e substratos estão apresentadas nas tabelas 2 e 3. Pode-se observar que o aparecimento de raízes adventícias na superfície do substrato ocorreu aos 28 dias após a instalação do experimento.

Tabela 2. Porcentagens totais acumuladas de alporques de C. quercifolius enraizados, em função das doses de AIA (Patos, PB, 2010).

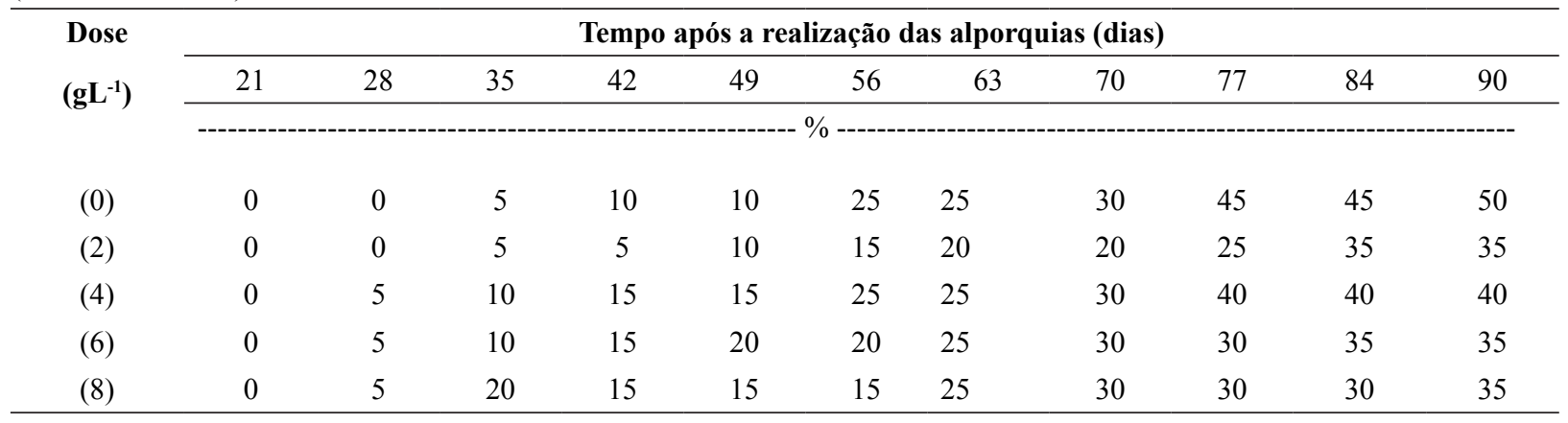

$0=$ controle; $2=2 \mathrm{gL}^{-1}$ de AIA; $4=4 \mathrm{gL}^{-1}$ de AIA; $6=6 \mathrm{gL}^{-1}$ de AIA $; 8=8 \mathrm{gL}^{-1}$ de AIA. 
Tabela 3. Porcentagens totais acumuladas de alporques de C. quercifolius enraizados, em função do substrato (Patos, PB, 2010).

\begin{tabular}{|c|c|c|c|c|c|c|c|c|c|c|c|}
\hline \multirow[t]{2}{*}{ Sub } & \multicolumn{11}{|c|}{ Tempo após a realização das alporquias (dias) } \\
\hline & 21 & 28 & 35 & 42 & 49 & 56 & 63 & 70 & 77 & 84 & 90 \\
\hline 1 & 0 & 6 & 10 & 12 & 12 & 12 & 16 & 24 & 26 & 28 & 30 \\
\hline 2 & 0 & 0 & 6 & 12 & 16 & 28 & 32 & 32 & 42 & 44 & 46 \\
\hline
\end{tabular}

De forma geral, a maioria dos alporques emitiu suas primeiras raízes adventícias na superfície do substrato, por volta dos 35 dias após a instalação do experimento. Campos (2010) observou o aparecimento das primeiras raízes em alporques de faveleira aos 42 dias após a instalação dos alporques. As primeiras raízes surgidas na superfície dos alporques ocorreram nos tratamentos que apresentaram as maiores concentrações de AIA (Tabela 2). Houve maior número de alporques enraizados na concentração intermediária de $\operatorname{AIA}\left(4 \mathrm{gL}^{-1}\right)$ ao final do experimento. De acordo com Pasqual et al. (2001), a utilização de auxinas possibilita a aceleração da formação de raízes em espécies que apresentam difícil enraizamento.

Foi observada precocidade de enraizamento com o uso de vermiculita, entretanto, até o final do experimento, percebeu-se um maior incremento de enraizamento com o uso do rejeito de vermiculita (Tabela 3).

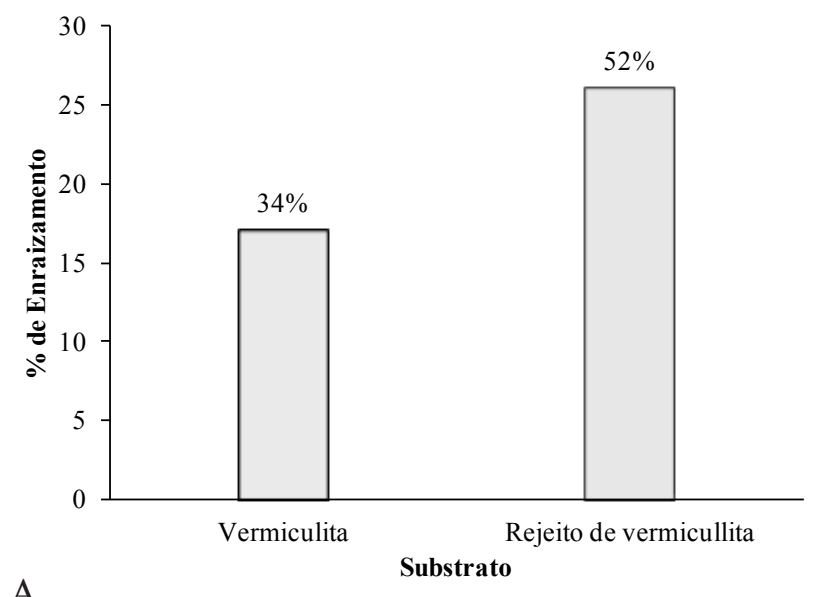

A

Figura 1. Porcentagem de enraizamento (A) e médias originais do número de raízes (B), por substrato, em C. quercifolius, aos 90 dias após a realização das alporquias (Patos, PB, 2010).
Os resultados da análise de variância da porcentagem de enraizamento e número de raízes revelam que não houve variação significativa $(\mathrm{p}>0,05)$. Houve sucesso de enraizamento em $43 \%$ das alporquias realizadas, concordando com os resultados obtidos por Campos (2010), trabalhando com a mesma espécie e usando substrato comercial e vermiculita. Já Noberto (2010), em estudo de propagação vegetativa por estaquia em faveleira, obteve porcentagens de enraizamento bem menores, em torno de $15 \%$.

O substrato rejeito de vermiculita apresentou em valor absoluto maior eficiência que a vermiculita para as duas variáveis (Figura 1), embora não tenha sido constatada diferença significativa $(\mathrm{p}>0,05)$. O melhor desempenho do rejeito pode ser explicado em parte pela sensível superioridade no teor de fósforo no rejeito de vermiculita (40 mg. $\mathrm{kg}^{-1}$ em relação ao observado na vermiculita (12 mg. $\mathrm{kg}^{-1}$ ) (Tabela1).

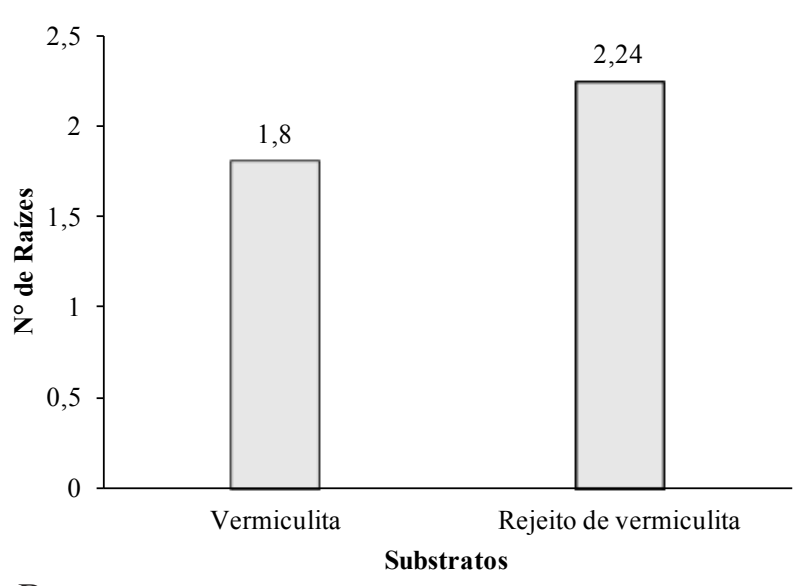

B 
Segundo Franco et al. (2005), o maior volume de raízes é fator imprescindível para garantir o sucesso na instalação do pomar, pelo efeito na maior taxa de pegamento das plantas em campo. Segundo Couvillon (1988), o substrato pode ser determinante para o sucesso do enraizamento de algumas espécies vegetais. De acordo com Ferraz et al. (2005), pode-se considerar difícil a obtenção de um substrato que atenda a todas as características físicas ideais para determinada cultura, devendo-se selecionar as características mais importantes do substrato para o crescimento de cada espécie vegetal.

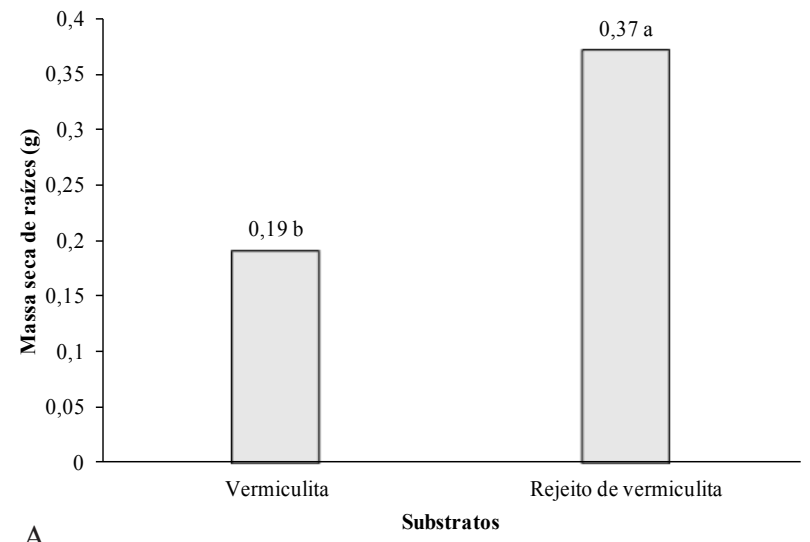

Para massa seca de raízes, foi constatada diferença significativa apenas para substratos $(\mathrm{p}<0,05)$. A análise de regressão aplicada às doses de AIA constatou que os dados de massa seca de raízes não se ajustaram a nenhuma das equações de regressão. $O$ rejeito de vermiculita foi mais eficiente que a vermiculita na produção de massa seca de raízes de faveleira (Figura2A).

Alguns trabalhos têm apresentado bons resultados acerca da utilização de rejeitos de mineração como constituinte de substratos para emergência e produção de mudas de algumas espécies de importância agroflorestal, como Moringa oleifera Lam. (Alves et al., 2005) e Jatropha curcas L. (Trajano et al., 2010).

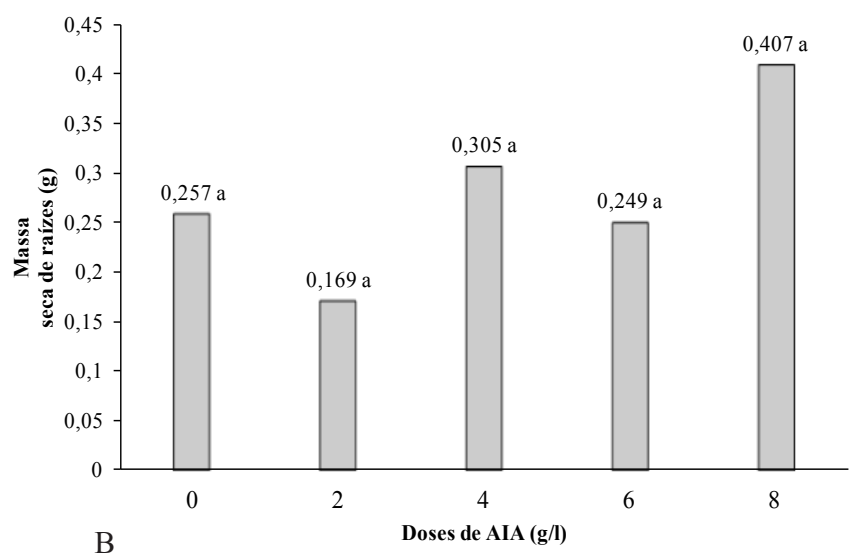

Figura 2. Médias da massa seca de raízes por substrato (A)e por dose de AIA (B), em C. quercifolius (faveleira), aos 90 dias após a realização das alporquias (Patos, PB, 2010). Médias seguidas por letras diferentes diferem entre si pelo teste Tukey a 5\%.

De acordo com Mielke et al. (1994), diferentes combinações entre auxinas e cofatores do enraizamento, estimulados pelo suprimento constante de elementos minerais, podem ser as causas das variações ocorridas na emissão e desenvolvimento de raízes nas diferentes plantas utilizadas nos alporques.

\section{Conclusões}

O Ácido Indol Acético (AIA) não influenciou significativamente nenhuma das variáveis analisadas. O substrato rejeito de vermiculita teve um desempenho superior em todas as variáveis estudadas, influenciando significativamente a produção de massa seca radicular da faveleira. Isso mostra sua grande importância como substrato alternativo para a produção de mudas, sobretudo pela fácil aquisição e baixo custo.
Sua utilização como substrato revela-se como uma alternativa ecológica viável para a redução dos impactos ambientais provocados pela emissão e acúmulo deste resíduo no ambiente.

\section{Referências}

ALVES, J. C.; PÔRTO, M. L.; SOUZA, A, P.; ANDRADE, L. A.; SILVA, G. B. Produção de mudas de moringa em substratos com níveis crescentes de rejeito de caulim. In: CONGRESSO BRASILEIRO DE OLERICULTURA, 45., 2005. Resumos Expandidos. Fortaleza: SBF, 2005.

CAMPOS, G. N. F. Clonagem de Cnidoscolus phyllacanthus (Mart.) Pax et K. Hoffm. (faveleira) por alporquia. 2010. $45 \mathrm{f}$. Dissertação (Mestrado em Ciências florestais) - Universidade Federal de Campina Grande, Patos.

CAVAlCANTI, M. T.; BORA, P. S.; CARVAJAL, J. C. L. Propriedades funcionais de amêndoas de faveleira ( Cnidoscolus 
phyllacanthus (Mart.) Pax. et. K. hoffm.) com e sem espinhos. Ciência e Tecnologia de Alimentos, Campinas, v. 29, n. 3, p. 597602, 2009.

COUVILLON, G. A. Rooting response to different treaments. Acta Horticulturae, The Hague, v. 227, p. 187-196, 1988.

DANTAS, J. P.; NÓBREGA, S. B. P.; QUEIROZ, M. F.; LEÃO, A. C. A Faveleira [Cnidoscolus phyllacanthus (Mart). Pax et K. Hoffm] como fonte alternativa na alimentação humana e animal no Semi-Árido Paraibano. In: CONGRESSO BRASILEIRO DE AGRONOMIA, 23., 2003, Belo Horizonte. Agronomia: sustentabilidade, trabalho e qualidade de vida: anais. Belo Horizonte: CONFAEAB: SMEA, 2003.

DIAS, P. C.; OLIVEIRA, L. S.; XAVIER, L. A.; WENDLING, I. Estaquia e miniestaquia de espécies florestais lenhosas do Brasil. Pesquisa Florestal Brasileira, Colombo, v. 32, n.72, p. 453-462, 2012. DOI: $10.4336 / 2012$.pfb.32.72.453

FERRAZ, M. V.; CENTURION, J. F.; BeUtler, A. N. Caracterização física e química de alguns substratos comerciais. Acta Scientia Agronomica, Maringá, v. 27, n. 2, p. 209-214, 2005.

FRANCO, C. F.; PRADO, R. M.; BRAGHIROLLI, L. F.; LEAL, R. M.; PEREZ, E. G.; ROMUALDO, L. M. Uso da poda e de diferentes diâmetros de alporques sobre o desenvolvimento e acúmulo de nutrientes de mudas de lichieira. Revista Brasileira de Fruticultura, Jaboticabal, v. 27, n. 3, p. 491-494, 2005.

HARTMANN, H. T.; KESTER, D. E.; DAVIS JUNIOR, F. T.; GENEVE, R. L. Plant propagation: principles e practices. New Jersey: Prentice Hall, 2002. 880 p.

MIELKE, M. S.; FACHINELLO, J. C.; NACHTIGAL, J. C.; MATIUZ, B.; ENDRES, L.; Comportamento fisiológico de goiabeira serrana quando multiplicada por mergulhia de cepa. Scientia Agricola, Piracicaba, v. 51, n. 1, p. 21-27, 1994.

NÓBREGA, S. B. P. A faveleira (Cnidoscolus quercifolius) como fonte alternativa na alimentação humana e animal no Semi-Árido Paraibano. 2001. 145 f. Dissertação (Mestrado em Desenvolvimento e Meio Ambiente) - Universidade Federal da Paraíba, João Pessoa.
NOBERTO, M. N. S. Efeito do ácido indol butírico e de substratos na clonagem de Cnidoscolus quercifolius Pohl, através de estaquia. 2010. 34 f. Monografia (Graduação em Engenharia Florestal) - Universidade Federal de Campina Grande, Patos.

PASQUAL, M.; CHALFUN, N. N. J.; RAMOS, J. D.; VALE, M. R. do; SILVA, C. R. R. Fruticultura comercial: propagação de plantas frutíferas. Lavras: UFLA; FAEPE, 2001. 137 p.

RIBEIRO FILHO, N. M.; CALDEIRA, V. P. S.; FLORÊNCIO, I. M.; AZEVEDO, D. O.; DANTAS, J. P. Avaliação comparada dos índices químicos nitrogênio e fósforo nas porções morfológicas das espécimes de faveleira com espinhos e sem espinhos. Revista Brasileira de Produtos Agroindustriais, Campina Grande, v. 9, n. 2, p. 149-160, 2007.

SILVA, F. A. S.; AZEVEDO, C. A. V. de. A new version of the assistat-statistical assistance software. In: WORLD CONGRESS ON COMPUTERS IN AGRICULTURE, 4., Orlando. Anais... Orlando: American Society of Agricultural Engineers, 2006. p. 393-396.

SILVA, C. C.; DANTAS, J. P; SANTOS, J. C. O.; SANTOS, T. T. S. Obtenção do biodiesel derivado do óleo de faveleira (Cnidosculus quercifolius) uma espécie forrageira. In: CONGRESSO NORTENORDESTE DE QUÍMICA, 1., 2007, Natal. [Anais eletrônicos]. Natal: Associação Norte-Nordeste de Química, 2007. Disponível em: $<$ http://www.annq.org/Congresso2007/trabalhos apresentados/T76. pdf $>$. Acesso em: 13 jan. 2010.

TRAJANO, E. V. A.; SANTOS, R. V.; BAKKE, O. A.; VITAL, A. F. M.; SANTOS, Y. M.; QUARESMA, J. M.; SALVIANO, V. M. Crescimento do pinhão manso em substratos com rejeitos de mineração do semiárido-PB. In: CONGRESSO BRASILEIRO DE MAMONA, 4.; SIMPÓSIO INTERNACIONAL DE OLEAGINOSAS ENERGÉTICAS, 1., 2010, João Pessoa. Inclusão social e energia: anais. Campina Grande: Embrapa Algodão, 2010.

WENDLING, I.; FERRARI, M. F.; GROSSI, F. Curso intensivo de viveiros e produção de mudas. Colombo: Embrapa Florestas, 2002. 48 p. (Embrapa Florestas. Documentos, 79). 